\title{
PERSPECTIVAS SOBRE O CONHECIMENTO DO PROFESSOR
}

\author{
Perspectives on teacher knowledge
}

\author{
Henrique Manuel Guimarães
}

Centro de Investigação em Educação e Departamento de Educação da Faculdade de Ciências da Universidade de Lisboa. Lisboa - Portugal, e-mail: hmg@fc.ul.pt

\begin{abstract}
Resumo
Este artigo é um ensaio teórico sobre o conhecimento do professor onde são confrontadas as perspectivas de três autores - Donald Schön, Freema Elbaz e D. Jean Clandinin - destacando, em cada um deles, as principais dimensões e componentes usadas na caracterização desse conhecimento. Tomamos como ponto de partida a crítica de Schön ao modelo da 'racionalidade técnica' e procuramos depois mostrar que esses autores desenvolvem a idéia de um saber específico do professor como um tipo de conhecimento que tem na prática, a um tempo, a sua fonte principal e lugar de manifestação. Pretendemos, igualmente, mostrar que com a idéia de 'conhecimento prático' defendida com uma natureza experiencial, situacional e pessoal - se procura evitar a sua identificação com um conhecimento meramente técnico e ultrapassar algumas dicotomias habituais no estudo e caracterização de formas de conhecimento, nomeadamente, teoria-prática, razão-emoção, objetivo-subjetivo, individualsocial, conteúdo-estrutura.
\end{abstract}

Palavras-chave: Conhecimento prático; Conhecimento do professor; Formação de professores.

Rev. Diálogo Educ., Curitiba, v. 8, n. 25, p. 819-839, set./dez. 2008 


\begin{abstract}
This article is a theoretical essay on teacher's knowledge confronting Donald Schön, Freema Elbaz and D. Jean Clandinin perspectives on that subject, trying to elicit the main dimensions and components they use to characterize teacher's knowledge. To begin with I take Schön's critique to technical rationality and then I try to show that the authors I mentioned developed an idea that teachers have a specific knowledge that both spring from, and is revealed in, the teaching practice. I also try to show that while using this notion of 'practical knowledge' - experiencial, situational and personal in nature - they refuse to reduce that knowledge to a mere technical knowledge and they intend to go beyond usual dichotomies - theory-practice, reason-emotion, objectivity-subjectivity, individual-social, content-structure - in the study and characterization of ways of knowing.
\end{abstract}

Keywords: Practical knowledge; Teacher's knowledge; Teacher education.

\title{
A crítica ao modelo da racionalidade técnica
}

Há um sentimento mais ou menos generalizado de que educação escolar está desadequada e que não satisfaz muitas das expectativas sociais actuais, sendo a responsabilidade principal desta situação atribuída aos professores e à Escola. Os resultados educativos, sobretudo na sua face mais visível - as elevadas taxas de reprovação e o desinvestimento e desinteresse dos alunos nas actividades escolares - são alimento do descrédito crescente em relação ao professor. Este sentimento de descrença em relação ao professor já não é recente e Donald Schön (1991) vai ao ponto de generalizar este descrédito a todas a profissões, falando em "crise de confiança" e "crise de legitimidade", querendo com isto significar uma espécie de "crescente cepticismo relativamente à benfeitoria e utilidade prática do conhecimento profissional e de um progressivo desacordo em conceder às profissões a autonomia, a autoridade e o controlo que habitualmente gozavam" (SCHÖN, 1992b, p. 119). Para este autor, a crise a que se refere é gerada por uma concepção do conhecimento profissional como aplicação instrumental do conhecimento científico e técnico aos problemas da prática. É o "modelo da racionalidade técnica" para o conhecimento

Rev. Diálogo Educ., Curitiba, v. 8, n. 25, p. 819-839, set./dez. 2008 
profissional, concepção epistemológica que o autor insere na corrente positivista nascida no século XIX, afirmando mesmo que a "racionalidade técnica é a epistemologia positivista da prática" (SCHÖN, 1991, p. 31).

Segundo esta visão, "a atividade profissional consiste na resolução de problemas instrumental (instrumental problem solving), tornada rigorosa pela aplicação da teoria e técnicas científicas" (SCHÖN, 1991, p. 21) e, assim, uma profissão é, acima de tudo, um veículo para aplicação dos conhecimentos científicos disponíveis à resolução dos problemas que essa profissão enfrenta. Em particular, deste ponto de vista, um professor é sobretudo um técnico que será considerado competente se aplicar de forma adequada o conhecimento produzido pela investigação científica (na matéria que ensina) ou educacional (didática, psicológica, pedagógica). Nas universidades produz-se (organiza-se, sistematiza-se, legitimase) os conhecimentos científicos que as profissões devem aplicar e a prática profissional consistirá na aplicação dos saberes (científicos, técnicos) aprendidos. Formar um profissional é, assim, ensinar-lhe os saberes científicos e técnicos considerados necessários à sua profissão que, numa perspectiva de ciência aplicada, terá que utilizar para resolver os problemas da sua prática.

Esta perspectiva, como Donald Schön (1991, p. 16) salienta, veio a mostrar-se redutora e incompleta. Apesar do desenvolvimento científico e tecnológico das últimas décadas, muitos dos graves problemas sociais não foram resolvidos, tendo surgido novos problemas cuja origem se associa, muitas vezes, ao próprio desenvolvimento científico. $\mathrm{Na}$ análise que faz, Schön considera que esta situação contribuiu para a crise de confiança e cepticismo referidos e, para explicar esta crise, convoca razões de vária ordem, no centro das quais coloca a desadequação do conhecimento profissional e dos processos de formação, face à prática a que supostamente se referem. O modelo da racionalidade técnica, diznos, não se adequa às situações da prática com que nos deparamos, uma vez que elas não se apresentam como problemas claramente definidos para serem solucionados, mas como "situações problemáticas caracterizadas pela incerteza, desordem e indeterminação."

As situações da prática profissional não são simples, estáticas, estruturadas ou uniformes mas, pelo contrário, como Schön (1991) sublinha, são situações de elevada complexidade, de carácter único, instáveis e em que existem conflitos. É este tipo de situações que o profissional defronta (muito evidentes em educação) e para as quais a formação tradicional - que poderíamos traduzir de forma simples por aprender para aplicar - é inadequada. A ciência e a técnica não contem todas as respostas às questões e problemas que a prática levanta e existem elementos essenciais no conhecimento profissional que só se manifestam e desenvolvem na prática. Desta análise decorre a proposta de uma epistemologia da prática que, ao contrário da racionalidade técnica, reconheça e integre elementos

Rev. Diálogo Educ., Curitiba, v. 8, n. 25, p. 819-839, set./dez. 2008 
dessa prática. "Se o modelo da racionalidade técnica é incompleto na medida em que não contempla as competências práticas que situações 'divergentes' exigem", diz o autor, "procuremos, em seu lugar, uma epistemologia da prática implícita nos processos intuitivos e artísticos que alguns profissionais desenvolvem em situações de incerteza, instabilidade, singularidade e de conflito de valores" (SCHÖN, 1991, p. 49). Atribui-se, assim, à prática um valor epistemológico considerando-a como fonte de conhecimento profissional, o que equivale a reconhecer, nesse conhecimento, uma componente que os profissionais adquirem e desenvolvem em situações dessa prática.

\section{A noção de conhecimento prático}

Analisando a investigação sobre os professores, Gary Fenstermacher confronta dois tipos de conhecimento: o conhecimento formal e o conhecimento prático. O primeiro, é apresentado como o conhecimento obtido com o recurso aos "métodos científicos convencionais, quantitativos ou qualitativos, [...] pretendendo proporcionar graus de significância, validade, generalização e intersubjetividade comunmente aceitos" (FENSTERMACHER, 1994, p. 8). Associando o conhecimento formal à ciência convencional, o autor diz que é esta a concepção de conhecimento que está na base da "abordagem de orientação científica" (science-oriented approach) e considera-o como "uma modificação do que é conhecido como uma explicação padrão (standard), ou baseada em crenças verdadeiras justificadas (justified true belief) do conhecimento humano" (FENSTERMACHER, 1994, p. 8).

Para caracterizar melhor o conhecimento formal, Fenstermacher, recorrendo à epistemologia, relaciona-o com o conceito de conhecimento proposicional, muitas vezes referido, diz-nos, como conhecimento teórico ou científico e associado à noção grega de epistèmè, significando "o conhecimento do mundo que pode ser estabelecido com um nível de confiança muito elevado" (FENSTERMACHER, 1994, p. 21), e cujo paradigma é o conhecimento científico. O conhecimento formal é apresentado com fortes relações com os métodos de investigação científica e associado a níveis de significância, validade e generalização determinados, sendo exigido que "seja justificado de tal modo que ultrapasse o contexto, situação ou período de tempo imediatos" (FENSTERMACHER, 1994, p. 28).

O segundo tipo de conhecimento - o conhecimento prático - énos descrito por Fenstermacher como um conhecimento inerente às situações da prática, que se desenvolve a partir das ações que as pessoas realizam e da

Rev. Diálogo Educ., Curitiba, v. 8, n. 25, p. 819-839, set./dez. 2008 
reflexão que fazem sobre elas. Para o autor, este tipo de conhecimento, ao contrário do conhecimento formal, tem um carácter situacional e contextual, é de natureza experiencial e não necessariamente explícito. Trata-se, segundo as suas próprias palavras, de um conhecimento que é "circunscrito à situação ou contexto onde nasce e pode ou não ser susceptível de expressão, escrita ou oral, imediata; [...] [que] se relaciona geralmente com o saber fazer as coisas, com o saber o lugar e tempo certos para as fazer, e com o ser capaz de ver e interpretar acontecimentos relacionados com as ações que realizamos" (FENSTERMACHER, 1994, p. 12).

Fenstermacher, recorrendo também à epistemologia, confronta o conhecimento prático com o "conhecimento de desempenho" (performance knowledge), expressão usada englobando noções como "saber fazer" (knowing how), "conhecimento de técnicas" (skill knowledge) e "desempenho competente" (competent performance). Esse tipo de conhecimento é associado à noção grega de techné - no sentido de habilidade, de saber como fazer alguma coisa - associação que no entanto "não significa sugerir que se esteja a lidar apenas com uma forma de saber fazer (know-how)" (FENSTERMACHER, 1994, p. 25). Rejeita assim a dicotomia "saber-saber fazer" (knowin that-knowing how), considerando que, embora tratando-se de saberes distintos, eles são "interdependentes". [...] "não podemos optar pelo conhecimento de desempenho sem também compreender que, no processo, 'adquirimos' conhecimento proposicional e vice-versa" (FENSTERMACHER, 1994, p. 27).

Tal como procedeu na comparação entre o conhecimento formal e o proposicional, Fenstermacher distingue o conhecimento prático do conhecimento de desempenho (performance knowledge), na forma como os epistemólogos o entendem. Considera o primeiro um "conceito mais amplo e mais inclusivo" (FENSTERMACHER, 1994, p. 28), englobando noções como o "conhecimento estratégico" (SCHULMAN, 1986, p. 36) e a idéia de "sabedoria prudencial" (prudencial wisdom, atribuída a Jonsem e Toulmin) que cita como exemplos. Referindo-se aos professores, Fenstermacher diz que, no ensino, o conhecimento prático é "mais do que technè, mais do que saber fazer, é um conceito colectivo relativo à vida mental dos professores, aos seus pensamentos, reflexões, propósitos, planos, desejos", incluindo ainda a ideia de experiência vivida que vai buscar junto a John Dewey. É precisamente este tipo de conhecimento que tem vindo a ocupar lugar de relevo no estudo do conhecimento do professor e sobre o qual tem vindo a desenvolver-se cada vez mais estudos (CLANDININ, 1986; ELBAZ, 1983; FENSTERMACHER, 1994; MUNBY, 1992; SCHÖN, 1991).

Rev. Diálogo Educ., Curitiba, v. 8, n. 25, p. 819-839, set./dez. 2008 


\section{O "conhecimento-na-acção" e a "reflexão-na-ação" de D. Schön}

Segundo Donald Schön (1991, p. 49), o "conhecimento-na-ação" (knowing-in-action) é o saber que os profissionais manifestam na prática quando executam (bem, competentemente) uma determinada ação. Como a expressão indica, é um saber na ação e este na tem um duplo sentido de inclusão e simultaneidade. Isto é, por um lado, é um saber incorporado na ação, é um saber que "está na nossa ação". Por outro lado, é um saber que se manifesta durante a ação, enquanto ela decorre. É, assim, inseparável da ação e, em determinados casos, também inseparável dos objetos com os quais agimos. De algum modo, como também refere Schön, é o que o senso comum chama de "saber-fazer". Este tipo de conhecimento é descrito do seguinte modo:

- é tendencialmente tácito (implícito): ou seja, é dificilmente verbalizável ou de difícil descrição; sabemos fazer uma coisa e não conseguimos dizer o que sabemos para (se ser capaz de) fazer essa coisa;

- tem carácter de espontaneidade: não precisamos pensar para o usar, nem enquanto o usamos (tem muitas vezes caráter quase automático);

- $\quad$ surge-nos como intuitivo: empregamo-lo sem que muitas vezes tenhamos consciência de o termos aprendido (SCHÖN, 1991, 1992a).

Para Donald Schön (1991, p. 54) o conhecimento-na-ação, entendido desta maneira, é o "modo característico do conhecimento prático comum". Um outro modo de conhecimento prático que este autor apresenta e discute é o que chama de "reflexão-na-ação" (reflection-in-action). Tal como o primeiro, este também é uma modalidade de conhecimento inerente à própria ação, ou seja, inseparável da prática onde se constitui e revela. É um movimento do pensamento que ocorre na ação, enquanto a ação se processa. Não se trata no entanto, como o autor salienta, do "parar-para-pensar" que a palavra reflexão pode sugerir, mas do pensar sobre o que se está a fazer, enquanto se faz. É uma reflexão que ocorre durante a ação, sem que esta tenha que ser interrompida, e que não obriga ao emprego de palavras.

1 SCHÖN, D. The theory of inquiry: dewey's legacy to education. Curriculum Inquiry, v. 22, n. 2, p. 119-139, 1992b. refere Hannah Arendt, distinguindo a noção de parar-para-pensar (stop-andthink) desta autora, do seu conceito de reflexão-na-ação. A noção de Arendt é descrita como uma "pausa durante a qual pensamos retrospectivamente sobre o que fizemos, raciocinando verbalmente ", enquanto que a reflexão-na-ação "ocorre em plena ação", durante o que designa por action-present sem que, necessariamente, se tenham que usar palavras.

Rev. Diálogo Educ., Curitiba, v. 8, n. 25, p. 819-839, set./dez. 2008 
A reflexão-na-ação pode ser verbal ou não verbal, isto é, pode verificar-se no seio de interações verbais ou não. Pode ocorrer em situações em que não há palavras, e os exemplos que Schön (1992b, p. 125) nos dá referemse à atuação do jogador de basquetebol ao reagir em resposta à manobra de algum adversário e à do pianista que improvisa em resposta ao som de outro instrumento, situações em que o autor considera que os executantes "pensam no que estão fazendo enquanto o fazem", mesmo sem existirem palavras. Noutras situações, a reflexão ocorre no seio de uma interação verbal, como no diálogo entre duas pessoas que reagem às interpelações de uma à outra, ou como no caso do professor que procura perceber as reacções dos alunos no momento em que acontecem, e atuar em conformidade com o entendimento que fez. Referindo-se aos professores, (SCHÖN, 1992a, p. 83) dá-nos o exemplo de uma situação de reflexão-na-ação:

Existe, primeiramente, um momento de surpresa: um professor reflexivo permite-se ser surpreendido pelo que o aluno faz. Num segundo momento, reflete sobre esse fato, ou seja, pensa sobre aquilo que o aluno disse ou fez e, simultaneamente, procura compreender a razão porque foi surpreendido. Depois, num terceiro momento, reformula o problema suscitado pela situação [...]. Num quarto momento, efetua uma experiência para testar a sua nova hipótese, por exemplo, coloca uma nova questão ou estabelece uma nova tarefa.

Analisando esta situação podemos distinguir alguns momentos na atuação do professor, que esquematicamente podem ser expressos na sequência: surpresa - interpretação - reformulação - experimentação.

$\mathrm{Na}$ verdade, há, em primeiro lugar, a intervenção de um aluno que surpreende o professor. Em seguida, o professor procura compreender o que terá estado na origem dessa intervenção e por que razão terá se surpreendido. Reformula depois a situação de acordo com o entendimento que fez e, por fim, procura averiguar a adequação da interpretação realizada. Num caso como este, tudo se passa como se a pessoa desencadeasse uma "conversa com a situação" (conversation with the situation), ideia que Donald Schön (1992b, p. 125) introduz, fazendo notar o sentido metafórico com que o termo conversa é usado, uma vez que se trata de uma conversa com a situação e não sobre a situação (e que, para ocorrer, como vimos, pode não exigir sequer palavras). Deste modo, é reforçada a interação entre o sujeito e a situação, o movimento de vaivém entre eles como elemento essencial da reflexão-na-ação. Na nossa atuação provocamos transformações na situação e o entendimento que fazemos da 'resposta' da situação, leva-nos a

Rev. Diálogo Educ., Curitiba, v. 8, n. 25, p. 819-839, set./dez. 2008 
modificar a nossa atuação. "Conversamos com a situação com que nos defrontamos e, como numa conversa, 'ouvimos' a situação, o que nos permite modificar o nosso entendimento a seu respeito e nossa forma de atuar."

A reflexão-na-ação é pois um processo que possibilita a reformulação da nossa compreensão durante a própria ação. Este processo de reflexão-na-ação não é necessariamente rápido pois, estando circunscrito ao momento em que a ação ocorre, pode ser, conforme os casos, de minutos ou horas, dias, semanas ou meses: "o ritmo e duração de episódios de reflexão-na-ação variam com o ritmo e duração das situações da prática” (SCHÖN, 1991, p. 62).

Donald Schön propõe ainda um outro tipo de reflexão - "reflexãosobre-a-ação" (reflection-on-action) - que ocorre, não durante a ação, mas depois dela. É a situação em que o pensamento incide a posteriori sobre a ação, reconstruindo-a mentalmente ou com a utilização de registos, e em que a pessoa reflete sobre a sua atuação, agora usando palavras ou descrições verbais. Podemos dizer que este tipo de reflexão pressupõe a sequência: ação/observação reconstrução (da ação) - reformulação.

Trata-se de um processo já não de reflexão na prática, mas de reflexão sobre a prática, que incide sobre o conhecimento-na-ação e sobre a reflexão-naação ${ }^{2}$ (SCHÖN, 1992b). Este refletir sobre a reflexão-na-ação ${ }^{3}$ que Schön (1992a, p. 83) considera simultaneamente como "uma ação, observação e descrição [exigindo] o uso de palavras", e que, segundo alguns autores, é um processo que favorece o desenvolvimento do professor e o ajuda a "construir a sua forma pessoal de conhecer" (ALARCÃO, 1991, p. 9), representa um outro nível de reflexão, descrito do seguinte modo, no caso do professor:

É possível olhar retrospectivamente e reflectir sobre a reflexão-na-ação. Após a aula, o professor pode pensar no que aconteceu, no que observou, no significado que lhe deu e na eventual adoção de outros sentidos. (SCHÖN, 1992a, p. 82).

\footnotetext{
Regressando a Hannah Arendt, Schön identifica este outro processo de reflexão com a idéia de stop-and-think de Arendt: "aqui, o pensamento volta-se sobre si próprio, quer sobre o conhecimento-na-ação revelado por um padrão de comportamento, quer sobre a reflexão-naação que reformula a nossa compreensão em plena ação" (SCHÖN, 1992b, p. 126).

3 PEREZ, Angel. O pensamento prático do professor: a formação do professor como profissional reflexivo. In: NÓVOA, António (Ed.). Os professores e a sua formação. Lisboa: D. Quixote, 1992. p. 94-114., socorrendo-se de Habermas, designa este processo reflexivo, a par com a reflexão-sobre-a-ação, por "reflexão crítica", considerando-o como o processo pelo qual o indivíduo analisa "as características e processos da sua própria ação," fazendo notar que seria mais adequado utilizar outro tipo de terminologia: "reflexão sobre a representação ou reconstrução a posteriori da ação".
}

Rev. Diálogo Educ., Curitiba, v. 8, n. 25, p. 819-839, set./dez. 2008 
No seu conjunto, o "conhecimento-na-ação", a "reflexão-na-ação" e a "reflexão-sobre-a-ação" constituem as modalidades de conhecimento prático na perspectiva de Donald Schön, modalidades estas que não são independentes mas que se interligam e completam. Este conhecimento é identificado por Angel Pérez (1992, p. 102) com a "capacidade para manejar a complexidade [das situações da prática] e resolver os problemas práticos através da integração inteligente e criativa do conhecimento e da técnica."

\section{O conhecimento prático em Freema Elbaz}

Num trabalho iniciado em 1976 e que se prolongou durante dois anos, Freema Elbaz (1983, p. 4) estudou em profundidade uma professora sob uma perspectiva em que o professor é visto como "um agente" com um papel "ativo e autónomo" na sua prática e, segundo a qual, essa prática "modela" o papel que o professor assume. Com o propósito de "ilustrar e conceptualizar" esse papel, dando ênfase particular ao "conhecimento que a professora possui e que usa no seu trabalho", procurou investigar o que designou por conhecimento prático que descreve assim:

Este conhecimento engloba experiência em primeira mão dos estilos de aprendizagem dos alunos, [dos seus] interesses, necessidades, capacidades e dificuldades, e um repertório de técnicas de ensino e de competências para a gestão da aula. O professor conhece a estrutura social da escola e o que ela exige [...], bem como a comunidade a que a escola pertence e tem uma sensibilidade daquilo que será ou não aceite por ela. (ELBAZ, 1983, p. 5).

Freema Elbaz atribui, assim, ao conhecimento prático um carácter experiencial e um conteúdo que abarca aspectos relacionados com os alunos e a aprendizagem, com o professor e o ensino e com o contexto escolar e social. É um tipo de conhecimento que o professor adquire e desenvolve com a sua experiência, mas que Elbaz relaciona com conhecimentos de outra natureza, proporcionados pelas áreas científicas da disciplina de lecionação e de domínios como a aprendizagem, a Psicologia e a Sociologia, e a que chama conhecimento teórico. " "Este conhecimento experiencial", diz a autora referindo-se ao

4 Podemos evocar aqui o "conhecimento formal" ou o "conhecimento proposicional" que Gary Fenstermacher analisou em The knower and the known: the nature of knowledge in research on teaching (Fenstermacher, G. The knower and the known: the nature of knowledge in research on teaching. Review of Research in Education, v. 20, p. 3-56, 1994).

Rev. Diálogo Educ., Curitiba, v. 8, n. 25, p. 819-839, set./dez. 2008 
conhecimento prático, "é informado pelo conhecimento teórico do professor" (ELBAZ, 1983, p. 5). É interessante o paralelo com Fenstermacher (1994) quando este, distanciando-se de uma posição que vê a ciência como fundamento do ensino, considera que "ensinar é uma prática informada e auxiliada pela ciência convencional, [mas] não tem por base [essa ciência]" (ELBAZ, 1983, p. 43). Para Elbaz, todos estes tipos de conhecimento, experienciais e teóricos, "tal como são integrados pela pessoa do professor, em termos de crenças e valores pessoais, e na medida em que são orientados para a sua situação prática" (ELBAZ, 1983, p. 5), constituem o conhecimento prático do professor, atribuindo-lhe assim, para além da natureza experiencial já referida, um carácter pessoal e situado ou contextual.

Frema Elbaz justifica a escolha da expressão "conhecimento prático" por um lado, por esta expressão chamar a atenção para o fato de a situação em que o professor se insere ser uma situação de ação e de tomada de decisões e, por outro lado, por considerar que o conceito que lhe está subjacente explica o conhecimento do professor "em função da sua resposta a essa situação" (ELBAZ, 1983, p. 5). Existe nesta justificação uma valorização da prática, da ação do professor, como fonte do conhecimento do professor e local privilegiado onde esse conhecimento se revela. Segundo esta perspectiva, poderemos compreender o conhecimento do professor se analisarmos a sua prática, embora essa análise só em parte explique esse conhecimento. A razão de ser do 'em parte' referido tem a ver com conhecimentos do professor de outra natureza, como se torna claro no exemplo fornecido para uma professora de História:

\begin{abstract}
O seu conhecimento pode ser estabelecido parcialmente de acordo com a teoria particular da História que ela adota, parcialmente em termos da organização imposta pelo livro de texto preferido e parcialmente em termos da experiência que tem de aspectos como os tópicos que os alunos acham mais relevantes e interessantes. (ELBAZ, 1983, p. 5).
\end{abstract}

São claros, nesta descrição do conhecimento da professora, elementos de natureza experiencial (os interesses dos alunos), elementos de natureza teórica, relacionados com a disciplina lecionada, e elementos de carácter 'misto', relacionados com a escolha do livro de texto, uma vez que podemos ver esta escolha orientada por conhecimentos teóricos e experienciais. Este exemplo dá uma ideia de como o conhecimento do professor é informado por conhecimentos de natureza diversa, cuja integração é realizada pela pessoa do professor de acordo com as suas concepções sobre a disciplina que leciona e preferências (em relação ao livro de texto), e tendo em conta o conhecimento dos alunos (proveniente da sua prática).

Rev. Diálogo Educ., Curitiba, v. 8, n. 25, p. 819-839, set./dez. 2008 


\section{Conteúdo, orientações e estrutura do conhecimento prático}

Na conceptualização que faz do conhecimento prático, Freema Elbaz (1983, p. 14) centra-se em três aspectos. Em primeiro lugar, analisa o seu conteúdo, pressupondo que o conhecimento prático é sobre alguma coisa e não apenas, como diz, um "conhecimento de como fazer coisas". Recusa, portanto, uma visão do conhecimento prático como um simples saber-fazer - recusa já evidenciada em Fenstermacher (1994, p. 69-70) - e sublinha a importância em reconhecer um conteúdo nesse tipo de conhecimento dos professores:

Sinto que é importante reconhecer que os professores possuem realmente um conhecimento de conteúdo conhecimento proposicional sobre o estado das coisas, crenças e coisas semelhantes - e que esse conhecimento é geralmente subvalorizado, apenas porque parece mais pobre comparado com o conhecimento, aparentemente superior, dos especialistas nos vários campos. (ELBAZ, 1983, p. 14).

Vimos que para Fenstermacher (1994, p. 14), o conhecimento prático do professor engloba aspectos da sua vida mental, nomeadamente, os seus pensamentos, reflexões e propósitos. Na mesma linha, Elbaz inclui as crenças do professor nesse conhecimento mas considera ainda que ele engloba também conhecimento proposicional sobre determinados assuntos (como exemplo, refere que os professores tem um conhecimento de Psicologia (embora diferente e menos extenso que o do psicólogo). Para delimitar e caracterizar o conteúdo do conhecimento prático do professor, Elbaz estabelece cinco categorias: "o conhecimento de si próprio, do ambiente do ensino, do assunto ensinado, de desenvolvimento curricular, e, de ensino." Como a autora salienta, estas categorias não obedecem a divisões disciplinares academicamente instituídas, mas foram estabelecidas por, em seu entender, serem relevantes para os professores. A primeira refere-se ao conhecimento que o professor tem de si como pessoa, a segunda ao seu conhecimento do contexto escolar e social onde desenvolve a prática docente, a terceira diz respeito ao conhecimento do professor sobre a matéria que ensina, a quarta e a quinta, respectivamente, ao conhecimento curricular do professor e ao seu conhecimento relativo aos alunos e a processos de ensino e aprendizagem.

Em segundo lugar, Freema Elbaz refere-se ao que designa por orientaçôes do conhecimento prático do professor, significando com isso os diferentes modos como o professor "usa e mantém" o seu conhecimento, para as quais estabelece também cinco categorias: "orientação para as situações, orientação

Rev. Diálogo Educ., Curitiba, v. 8, n. 25, p. 819-839, set./dez. 2008 
pessoal, orientação social, orientação experiencial e orientação teórica" (ELBAZ, 1983, p. 14). Embora a expressão não seja utilizada, estas categorias permitem falar da natureza do conhecimento prático do professor, ou seja, de que tipo de conhecimento se trata e que características apresenta.

Considerar o conhecimento prático do professor orientado para as situações ou, como também diz, para a prática que o professor desenvolve, significa, como já foi evidenciado, atribuir-lhe uma natureza situacional, ou seja, reconhecer que, em alguma medida, é indissociável das situações práticas que os professores experimentam. No entanto, para Freema Elbaz, o caráter situado deste conhecimento não implica a idéia de que o professor precisa mais do conhecimento prático, do que do conhecimento teórico oriundo de outras disciplinas. "O conhecimento prático do professor não é uma compilação de conselhos práticos vindos de outros campos", diz a autora, acrescentando: "mas um corpo de conhecimentos orientado para um contexto prático particular" (ELBAZ, 1983, p. 15). Este corpo de conhecimentos pode ser informado por outros campos científicos, mas é o contexto particular para que está orientado que determina a escolha da informação que é integrada, independentemente da natureza teórica ou prática dessa informação. Recorrendo à Psicologia, Elbaz dá um exemplo em que determinados instrumentos práticos usados pelos psicólogos podem ser totalmente inadequados no ensino e o mesmo não acontece com certos conhecimentos teóricos dessa ciência.

Com duas das outras orientações atribuídas ao conhecimento prático do professor - a orientação pessoal e a orientação social - Freema Elbaz reconhece, nesse conhecimento, uma determinante com origem no indivíduo e uma determinante com origem na sociedade. Assim, por um lado, o conhecimento prático é pessoal na medida em que existe "uma necessidade pessoal em integrar, ordenar e dar sentido à experiência de cada um” (ELBAZ, 1983, p. 16). Trata-se, no fundo, do reconhecimento da existência de uma perspectiva própria em cada indivíduo, a partir da qual ele percepciona, analisa e interpreta as situações que enfrenta e de que os objectivos do indivíduo e os significados que elabora desempenham um papel nesse processo. Nessa perspectiva, Elbaz inclui "não só concepções intelectuais, mas também percepções, sentimentos, valores, propósitos e interesses" (ELBAZ, 1983, p. 17). Por outro lado, o conhecimento prático tem também um carácter social na medida em que é "socialmente condicionado", carácter que se revela, como diz a autora referindo-se ao caso que estudou, "no modo como a professora, por exemplo, irá adaptar o assunto a tratar de forma a ter em conta os fatores étnicos ou economicos que influenciam as expectativas, interesses e sentido cívico dos seus alunos (ou dos pais)" (ELBAZ, 1983, p. 18).

Freema Elbaz considera ainda o conhecimento prático como experiencial e teórico. Aqui, também, uma dupla determinação desse conhecimento, agora segundo uma outra dimensão, a dimensão teoria-prática.

Rev. Diálogo Educ., Curitiba, v. 8, n. 25, p. 819-839, set./dez. 2008 
Por um lado, recorrendo a autores da fenomenologia como Schutz e Luckmann, considera o mundo da experiência, com as suas "províncias da realidade" vida quotidiana, sonhos, ciência, religião - onde inclui o "mundo do ensino", como elementos estruturadores do conhecimento prático. Provém daqui o seu caráter experiencial, de alguma forma já contido, como a autora salienta, nas três características - situacional, pessoal e social - já descritas. Por outro lado, considera que no conhecimento prático existem elementos teóricos, uma "orientação teórica", para usar a sua terminologia, reconhecendo a existência de conexões entre o conhecimento prático e o conhecimento teórico, dizendo mesmo que esse conhecimento "é mantido numa relação particular como o mundo da teoria" (ELBAZ, 1983, p. 21). Os professores, diz-nos, "são influenciados por formas de pensamento e de discurso que os cercam; a sua formação academica aprofunda, invariavelmente, tais influências e instila concepções teóricas, concepções de conhecimento válido [e] de pesquisa" (ELBAZ, 1983, p. 21), concepções estas que, uma vez integradas, fazem parte do conteúdo do seu conhecimento.

Em terceiro lugar, e por último, na conceptualização que faz do conhecimento prático dos professores, Freema Elbaz propõe uma estrutura, ou seja, um conjunto de componentes e suas relações, para esse tipo de conhecimento. Considerando que é este conhecimento que orienta o professor na sua prática, pressupõe a existência de alguma forma de organização interna, uma vez que sem tal organização, o conhecimento não seria mais que um conjunto de "receitas" desordenado - "um livro de cozinha sem índice" (ELBAZ, 1983, p. 21) - sem possibilidade de poder constituir qualquer orientação. A estrutura proposta é uma organização hierarquizada por graus ou níveis de generalidade, a cada um dos quais a autora associa diferentes tipos de "instrumentos de ordenação" (ordering devices). Apresenta três tipos de conhecimento, correspondendo a diferentes níveis de generalidade: dos mais específicos, que designou por "regras práticas" (rules of practice), aos mais gerais, "as imagens" (images), passando pelos "princípios práticos" (practical principles), estes de nível de generalidade intermédio (ELBAZ, 1983, p. 21).

A "regra prática" é definida como "uma formulação breve e clara do que há que fazer, ou de como o fazer, numa determinada situação que aparece frequentemente" (ELBAZ, 1983, p. 132); os "princípios práticos" são apresentados como formulações mais abrangentes e mais implícitas, "nas quais as intenções do professor, subentendidas na regra [de prática], são mais claramente evidentes" (ELBAZ, 1983, p. 133); as "imagens", ainda mais abrangentes e mais implícitas, são descritas como "noções muito amplas" que traduzem a perspectiva pessoal com que o professor se encara a si próprio, o ensino e a disciplina que leciona, por vezes formuladas na forma de metáforas e envolvendo juízos de valor.

Rev. Diálogo Educ., Curitiba, v. 8, n. 25, p. 819-839, set./dez. 2008 
Estes três tipos de conhecimento, para além de possuírem graus de generalidade diferentes, a que correspondem graus de explicitação também diferentes, traduzem também conexões diferentes entre o pensamento e a ação. Segundo a autora, as regras práticas são uma espécie de conhecimento disponível de que o professor se serve na sua ação para não precisar pensar; a sua utilização dispensa o pensamento. As imagens, ao contrário das regras, obrigam a pensar: "sem o pensamento, a imagem fica sem sentido, uma vez que sendo aberta assume diferentes significados em cada situação" (ELBAZ, 1983, p. 134). Para além disso, a regra prática é considerada mais exterior (ao sujeito) do que a imagem e, exercendo-se de fora para dentro, impõe-se obrigando uma atuação em conformidade. A imagem, mais interior, traduz uma intencionalidade, um propósito, e exerce-se mais de dentro para fora, "inspirando, mais do que exigindo conformidade" (ELBAZ, 1983, p. 134). Quanto aos princípios práticos, são apresentados como podendo atuar dos dois modos.

De uma forma simples podemos dizer que a regra prática está mais próxima da ação enquanto que a imagem está mais próxima da intenção. Entre as duas, o princípio prático, incluindo, como a regra, indicações sobre o que fazer e como fazer em determinadas situações, contém também indicações sobre as razões e propósitos que conduziram a pessoa na ação realizada. Por isso, o carácter pessoal do conhecimento é mais vincado (ou evidente) nos princípios do que nas regras práticas e, mais ainda, nas imagens.

Assim, em síntese, o conhecimento prático do professor, para Freema Elbaz, não é um mero saber-fazer, mas possui um conteúdo relativo a diversas áreas, desde a matéria ensinada, à própria pessoa do professor, desde as questões de ensino e de natureza curricular, ao contexto escolar e social em que a sua prática decorre. É um conhecimento essencialmente orientado para as situações que o professor enfrenta na sua ação educativa, de natureza, simultaneamente, pessoal e social, e, experiencial e teórica, e que se encontra hierarquizado em diferentes níveis de generalidade e de vínculo com a situação (a ação) ou com a pessoa. Estes níveis não estão isolados ou desligados uns dos outros mas, pelo contrário, existe inter-relação entre eles: "um princípio ou uma imagem podem dar origem a várias regras que os exemplificam; uma imagem pode desenvolverse a partir de princípios e regras que concorrem para ela" (ELBAZ, 1983, p. 138).

\section{Jean Clandinin e o "conhecimento prático pessoal"}

Na linha de pensamento de Donald Schön e de Freema Elbaz, D. Jean Clandinin tem vindo a desenvolver um programa de trabalho onde a ideia de conhecimento prático tem também um papel central (CLANDININ, 1985, 1986, 1987; CLANDININ; CONNELLY, 1987). Colocando-se igualmente numa perspectiva

Rev. Diálogo Educ., Curitiba, v. 8, n. 25, p. 819-839, set./dez. 2008 
em que o professor é visto como um sujeito ativo e autonomo na prática que realiza, Clandinin considera-o também como possuidor de um conhecimento específico que se constitui e desenvolve em estreita relação com essa prática. Desta maneira, propõese contrariar uma visão corrente do professor como veículo de um conhecimento que lhe é exterior, como alguém a quem não se reconhece um saber próprio: "os professores são vistos como possuindo experiência mas não conhecimento" (CLANDININ, 1986, p. 3). É a insatisfação com esta visão, como a autora o exprime, o que constituiu a grande motivação para o trabalho que desenvolveu onde, acima de tudo, pretende valorizar o conhecimento que admite o professor possuir.

Clandinin reconhece o trabalho de Frema Elbaz (1983) como precursor da sua própria investigação sobre o conhecimento do professor. ${ }^{5}$ De fato, citando a própria Freema Elbaz, CLANDININ (1986, p. 4) caracteriza este conhecimento apresentando-o como um conhecimento "prático, experiencial e modelado pelas intenções e valores do professor". Apesar do qualificativo 'prático', esta autora recusa a separação tradicional entre conhecimento teórico e conhecimento prático, considerando que os professores desenvolvem um tipo especial de conhecimento que não é nem teórico nem prático, mas "composto" por estes dois tipos de conhecimento numa combinação elaborada pela pessoa do professor, de acordo com as suas características pessoais e com a sua experiência e formação (CLANDININ, 1985). A esse conhecimento, chama "conhecimento prático pessoal" (personal practical knowledge) e relaciona-o com a necessidade da pessoa em desenvolver uma "linguagem" e uma "perspectiva" próprias para compreender e lidar com as situações da sua prática, considerando-o inseparável da pessoa que o elabora, bem como da situação (prática) onde se constitui e na qual se revela:

As ações são, simultaneamente, a expressão e a origem do conhecimento pessoal do ator. Assim, a ação está imbuída de conhecimento e o conhecimento de paixão. Ação e conhecimento estão unidos no ator e o que se diz sobre ambos diz respeito a um ator (em itálico no original). (CLANDININ, 1985, p. 361-362).

$\mathrm{Na}$ expressão conhecimento prático pessoal, Clandinin (1985) usa o termo 'conhecimento' referindo-se ao "conjunto de convicções" (body of convictions), neste caso, de um professor, que considera poderem ser conscientes ou inconscientes mas sempre com origem na experiência de cada um, seja ela de natureza mais pessoal

ELBAZ, Freema. Teacher thinking, a study of practical knowledge. Londres: Croom Helm, 1983. Cujo trabalho é um antecessor do meu próprio trabalho (CLANDININ, 1985, p. 364); "A presente investigação desenvolve-se com base na descrição (account) de conhecimento prático elaborada por Elbaz (1983)" (CLANDININ, D. Jean. Classroom pratice, teacher images in action. Londres: The Falmer Press, 1986. p. 19).

Rev. Diálogo Educ., Curitiba, v. 8, n. 25, p. 819-839, set./dez. 2008 
ou social, e que se revelam nas ações que o professor desenvolve. $\mathrm{O}$ adjetivo 'pessoal', diz-nos a autora, é utilizado querendo significar por um lado, que esse conhecimento está impregnado de tudo o que constitui o professor enquanto pessoa e, por outro lado, que o conhecimento é também parte da pessoa do professor. Trata-se assim de sublinhar a forte relação deste conhecimento, em termos do seu significado e compreensão, com a pessoa que o possui, com, como diz Clandinin, a sua história experiencial, pessoal e profissional. No que se refere ao qualificativo 'prático', a sua utilização pretende significar que se trata de um conhecimento que se revela na prática do professor e para cuja constituição e desenvolvimento essa prática desempenha um papel determinante. O termo 'prático', dizem Connelly e Clandinin (1986, p. 296), "qualifica o [nosso] interesse epistemológico alinhando-nos com autores como Schön cujo interesse é a epistemologia do pensamento prático."

Cada um dos três termos utilizados evidencia também as opções teóricas e metodológicas seguidas e demarcam o campo da investigação. O termo ‘conhecimento', segundo Connelly e Clandinin (1986, p. 297), evidencia o carácter epistemológico do trabalho desenvolvido, o termo 'prático', o interesse pela "epistemologia do pensamento prático", e, o termo 'pessoal' revela que esse interesse incide no modo como cada pessoa particular conhece as situações que vive. Trata-se, assim, de numa linha de valorização epistemológica da prática, estudar problemas do seu conhecimento do ponto de vista dos próprios professores. A expressão 'conhecimento prático pessoal', dizem os autores, "define o nosso interesse em compreender os atos de ensino em termos de explicações concretas personalizadas do conhecimento das pessoas."

Com esta ideia do conhecimento prático pessoal, como um conhecimento de carácter experiencial, transportando valores e propósitos do professor e orientado para a prática que ele desenvolve, Clandinin (1986, p. 20) considera esse conhecimento como "transitório", "sujeito a mudanças" e desenvolvendo-se num processo de tentativa-erro, demarcando-se da ideia de um conhecimento "fixo, objetivo e imutável". Passa por aqui, sublinhe-se, um certo distanciamento em relação a Donald Schön como significa a crítica à opção deste autor no estudo do conhecimento do professor: "o conhecimento que se persegue já não é objetivo tal como Schön o considera ao 'observar' (entre comas no original) as situações" (CONNELLY; CLANDININ, 1986, p. 296). ${ }^{6}$

6 CONNELLY, F.M.; CLANDININ, D. J. On narrative method, personal philosophy, and narrative unities in the story of teaching. Journal of Research in Science Teaching, New York, v. 23, n. 4, p. 293-310, 1986. Recusam quer o objetivismo de uma perspectiva que encara o conhecimento como independente do sujeito que conhece, quer o relativismo a que conduziria uma perspectiva meramente subjetivista; reclamam-se das idéias de Polanyi, considerando que o seu conceito de conhecimento pessoal resolve, dialeticamente, a oposição objetivo-subjetivo: "por 'conhecimento pessoal' Polanyi quer significar que o conhecimento não é objetivo [...] nem é meramente subjetivo [...] é, de um ponto de vista dialético, a resolução do subjetivo e do objetivo na pessoa, isto é, o pessoal" (CONNELLY; CLANDININ, 1986, p. 296).

Rev. Diálogo Educ., Curitiba, v. 8, n. 25, p. 819-839, set./dez. 2008 
Um outro ponto de distanciamento em relação a Donald Schön diz respeito ao fato de este encarar as situações que o professor enfrenta na sua prática como situações problemáticas, nomeadamente, no que se refere à noção de reflexãona-ação. Não contestando que o conceito de problema possa ter pertinência para o estudo das profissões em geral, Connely e Clandinin (1986), no entanto, colocam reservas à sua adequação para o estudo do que se passa na sala de aula do ponto de vista do professor. É assim que exprimem a sua preferência por outros conceitos que vão buscar em diversos investigadores ${ }^{7}$ e, particularmente, pelo conceito de imagem.

Na verdade, o conceito de imagem é um conceito central no trabalho de D. J. Clandinin (1986). Para esta investigadora, tal como para Elbaz (1983), as imagens são um componente do conhecimento prático do professor e, com a investigação que empreendeu, propõe-se precisamente a desenvolver uma conceptualização desse conceito. Do seu ponto de vista, como visto anteriormente, o conhecimento prático pessoal revela-se e desenvolve-se na prática do professor e é impossível compreendê-lo desligado dessa prática. A experiência que o professor vive impregna o seu conhecimento e as imagens constituem a forma como ela penetra esse conhecimento. Usando uma metáfora da autora, as imagens são uma espécie de cristalização da experiência que, deste modo, passa a fazer parte do conhecimento do professor. Para Clandinin, as imagens constituem "uma forma de organizar e reorganizar a experiência passada"; uma imagem, como também diz, "é um meta-conceito organizador pessoal [...] na medida em que incorpora a experiência da pessoa, se exprime na [sua] prática e é a perspectiva com a qual lida com novas experiências" (CLANDININ, 1986, p. 166).

Na conceptualização que propõe para a noção de imagem, Clandinin propõe três dimensões para a sua caracterização: a dimensão moral, a dimensão emocional e a dimensão ao nível do pessoal privado e profissional. Considera que as imagens contem e exprimem juízos de valor, permitindo ao professor julgar a sua própria prática: "As imagens não são [moralmente] neutras", diz-nos, "sugerem uma ação melhor ou pior" (CLANDININ, 1986, p. 147). Para além disto, considera que as imagens possuem "uma coloração emocional" e, por isso, também não são neutras do ponto de vista da afetividade, traduzem a orientação afetiva do professor face a determinada situação ou ação. É assim, pelas imagens, que os valores do professor e a sua afetividade penetram e constituem o seu conhecimento profissional. Além disso, para Clandinin, as imagens ligam mundos de experiência diferentes: "o constructo de imagem, na sua origem e nas funções que desempenha, liga a experiência privada pessoal e a experiência profissional educacional do

\footnotetext{
Trata-se de conceitos como os de "regra prática" e "princípio prático" (referidos, entre outros, a Freema Elbaz (1983) que também usa o conceito de "imagem"), de "filosofia pessoal", de "rotina", de "ritual, hábitos, ciclos e ritmos", estes referidos a investigadores diversos (CONNELLY; CLANDININ, 1986, p. 296).
}

Rev. Diálogo Educ., Curitiba, v. 8, n. 25, p. 819-839, set./dez. 2008 
indivíduo" (CLANDININ, 1986, p. 148). As imagens, como também diz, aglutinam estes dois tipos de experiência, são a "coalescência" destes dois mundos experienciais. É assim que, pelas imagens, o conhecimento profissional do professor incorpora elementos da experiência extra profissional.

\section{CONCLUSÃO}

Uma ideia generalizada, como diz Clandinin (1986, p. 9), "é que o professor não possui um corpo de conhecimentos exclusivo da sua profissão." Ao professor, como também diz, não se lhe reconhece conhecimento mas experiência; aquilo que a sua prática profissional lhe dará é tão só isso, experiência, sem estatuto de conhecimento. Deste ponto de vista, o conhecimento que se supõe o professor possuir, da matéria disciplinar que leciona ou das técnicas e processos, abordagens e teorias para seu ensino e aprendizagem, é um conhecimento que vai buscar a áreas científicas ou academicas exteriores à sua profissão. Assim, não se atribui aos professores um saber próprio, desenvolvido no quadro da sua prática profissional. Ou melhor, o saber específico que se admite possuírem é um saber desvalorizado face ao que é produzido por especialistas na investigação científica ou educacional: "o conhecimento é visto como sendo teórico e na posse de peritos; o conhecimento experiencial dos professores não é reconhecido" (CLANDININ, 1986, p. 3). O que se espera do professor é que use bem esse conhecimento e que o aplique competentemente, ficando-lhe reservado apenas o papel de "um mero agente realizando intenções de outrem" (CLANDININ, 1986, p. 3), transmitindo conhecimento que lhe é exterior.

Para os autores analisados, o professor possui um conhecimento profissional específico que é visto, essencialmente, como um conhecimento voltado para a ação, isto é, orientado para as situações da prática com que o professor lida e que lhe permite interpretá-las, agir sobre elas e apreciar os resultados da sua atuação. Esses autores, com maior ou menor ênfase, atribuem a esse conhecimento três características principais, ou, se quisermos, reconhecem-lhe uma tripla natureza: experiencial, situacional e pessoal. Experiencial, uma vez que o consideram como um conhecimento que os professores adquirem com a experiência, um conhecimento que tem origem na prática que os professores empreendem e que se desenvolve e manifesta nessa prática. Situacional, pois encaram-no como um conhecimento orientado para as situações que o professor enfrenta e, de certa maneira, indissociável dessas situações. Pessoal, significando com isto que todo o conhecimento tem por base uma perspectiva própria de cada pessoa, estando impregnado pelas concepções, valores e propósitos que constituem aquela perspectiva, a partir da qual o indivíduo percepciona e compreende o mundo e

Rev. Diálogo Educ., Curitiba, v. 8, n. 25, p. 819-839, set./dez. 2008 
desenvolve a sua atuação. Em Fenstermacher (1994) estão presentes estes três aspectos no modo como ele analisa o conhecimento prático; o carácter experiencial evidencia-se sobretudo nos conceitos de conhecimento-na-ação e reflexão-naação de Donald Schön (1991), enquanto que em Clandinin (1986) sobressai o carácter pessoal; Freema Elbaz (1983), por sua vez, a estes aspectos acrescenta ainda o que chamou de orientações social e teórica.

$\mathrm{Na}$ tentativa de valorização da profissão de professor, reconhecendo nela um saber específico com estatuto de conhecimento, introduz-se e desenvolvese a ideia de conhecimento prático do professor com as características atrás referidas. Nesse desenvolvimento detecta-se um esforço quer para evitar a identificação deste conhecimento com um conhecimento meramente técnico, quer para ultrapassar algumas dicotomias habituais no estudo e caracterização de formas de conhecimento, nomeadamente: teoria-prática, razão-emoção, objetivo-subjetivo, individual-social, conteúdo-estrutura.

Podemos ver esse esforço em Freema Elbaz (1983) quando, por exemplo, esta autora considera que o conhecimento prático, sendo pessoal, tem também uma determinante social e quando, ao caracterizá-lo como experiencial, lhe atribui também uma orientação teórica e o reconhece como sendo "mantido numa relação particular com o mundo da teoria", considerando que a formação academica do professor "instila concepções teóricas" (FREEMA, 1983, p. 21) que são integradas no seu conhecimento. Em Clandinin (1986), por sua vez, é saliente a consideração de elementos afetivos no conhecimento. $\mathrm{Na}$ conceptualização que faz do conhecimento prático pessoal do professor, utiliza o conceito de imagem como uma componente desse conhecimento, descrevendo-o em várias dimensões, entre as quais a dimensão moral e a emocional. Deste modo faz impregnar o conhecimento pelos valores e pela afetividade do professor.

Podemos ver também o esforço referido na consideração do elemento reflexivo no conhecimento do professor, por parte de Donald Schön (1991), bem como, em Fenstermacher (1994), na menção à interdependência entre o saber e saber fazer (knowing that, knowing how), rejeitando a dicotomia entre estes dois tipos de conhecimento. Também Freema Elbaz (1983) sublinha a importância em reconhecer que o conhecimento prático tem um conteúdo, que é "sobre alguma coisa" e não apenas um mero saber-fazer. Para esta autora, o conhecimento prático tem um conteúdo e uma estrutura que o organiza segundo níveis de diferentes graus de generalidade e diferentes relações com a pessoa e com a ação. Clandinin (1985), por sua vez, referese ao conceito de conhecimento prático pessoal como não sendo, nem apenas conteúdo, nem apenas estrutura, observação que vai buscar a M. Johnson numa análise ao trabalho de Freema Elbaz: "o conhecimento prático não é apenas conteúdo nem é apenas estrutura - é um exercício de capacidades num determinado contexto para a organização imaginativa da nossa experiência” (JOHNSON, 1984, p. 467).

Rev. Diálogo Educ., Curitiba, v. 8, n. 25, p. 819-839, set./dez. 2008 
No que se refere à dicotomia teoria-prática, Clandinin (1985) considera que o conhecimento que os professores desenvolvem não é nem teórico nem prático mas um conhecimento "especial" que descreve como sendo "composto" por aqueles dois tipos de conhecimento. Freema Elbaz (1983), por sua vez, vai ao ponto de incluir, no conteúdo do conhecimento prático, formas de conhecimento proposicional. Além disso, quando the atribui um caráter situacional, recusa a ideia de que ele possa ser considerado como uma "compilação de conselhos práticos" oriundos de outras áreas e a ideia de que o professor precisa mais do conhecimento prático do que do conhecimento teórico produzidos nessas áreas. A respeito das relações entre teoria e prática, estas autoras inserem-se uma perspectiva dialética considerando-as "inseparáveis" uma da outra, influenciandose e modelando-se reciprocamente.

Esta perspectiva faz-se também sentir no que se refere à dicotomia objetivo-subjetivo e no esforço feito para a ultrapassar. É assim que Connelly e Clandinin (1986) por um lado, não aceitam a ideia de um conhecimento puramente objetivo, do sujeito que conhece e, por outro lado, recusam a perspectiva relativista que vê o conhecimento como meramente subjetivo.

Rejeitando o modelo da racionalidade técnica, linhas de investigação como as que acabei de analisar propõem-se desenvolver uma epistemologia do conhecimento do professor que reconheça e integre a existência de elementos essenciais nesse conhecimento que só se desenvolvem e manifestam na prática do professor. Com a ideia de "conhecimento prático" pretende-se contrariar a visão da profissão de professor que a entende, essencialmente, como um exercício técnico no qual o professor é um mero veículo para a aplicação instrumental de um conhecimento que outros produzem. Contrapõe-se a ideia do professor como sujeito autónomo, sede de valores e intencionalidades, dotado, como diz Elbaz (1983, p. 6), de "recursos preciosos" que lhe dão capacidade de intervir no contexto em que se insere e de "determinar o estilo e objetivos do seu trabalho", valorizando-se assim o professor enquanto possuidor de um conhecimento próprio, específico da sua profissão.

\section{REFERÊNCIAS}

ALARCÃO, I. Reflexão crítica sobre o pensamento de D. Schön e os programas de formação de professores. Cadernos CIDINE, n. 1, p. 5-22, 1991.

CLANDININ, D. J. Personal practical knowledge: a study of teacher's classroom images. Curriculum Inquiry, v. 14, n. 4, p. 361-385, 1985.

Classroom pratice, teacher images in action. Londres: The Falmer Press, 1986.

Rev. Diálogo Educ., Curitiba, v. 8, n. 25, p. 819-839, set./dez. 2008 
CLANDININ, D. J.; CONNELLY, F. M. Teachers' personal knowledge: what counts as 'personal' in studies of the personal. Curriculum Inquiry, v. 19, n. 6, p. 487-500, 1987.

CONNELLY, F. M.; CLANDININ, D. J. On narrative method, personal philosophy, and narrative unities in the story of teaching. Journal of Research in Science Teaching, v. 23, n. 4, p. 293-310, 1986.

ELBAZ, F. Teacher thinking, a study of practical knowledge. Londres: Croom Helm, 1983.

FENSTERMACHER, G. The knower and the known: the nature of knowledge in research on teaching. Review of Research in Education, v. 20, p. 3-56, 1994.

JOHNSON, M. Review of 'teacher thinking: a study of practical knowledge'by Freema Elbaz. Curriculum Inquiry, v. 14, n. 4, p. 465468, 1984.

MUNBY, H. T. R. Frames of reflection: an introdution. In: RUSSEL, T.; MUNBY, H. (Ed.). Teacher and teaching: from classroom to reflection. Londres: The Falmer Press, 1992. p. 1-8.

PEREZ, A. O pensamento prático do professor: a formação do professor como profissional reflexivo. In: NÓVOA, A. (Ed.). Os professores e a sua formação. Lisboa: D. Quixote, 1992. p. 94-114.

SCHÖN, D. The reflective practitioner: how professionals think in action. Londres: Avebury, 1991.

Formar professores como profissionais reflexivos. In: NÓVOA, A. (Ed.). Os professores e a sua formação. Lisboa: D. Quixote, 1992a. p. 79-91.

The theory of inquiry: dewey's legacy to education. Curriculum Inquiry, v. 22, n. 2, p. 119-139, 1992b.

SCHULMAN, L. Those who understand. Educational Researcher, v. 15, n. 7, p. 4-14, 1986.

Recebido: 10/04/2008

Received: $04 / 10 / 2008$

Aprovado: 01/07/2008

Approved: 07/01/2008

Rev. Diálogo Educ., Curitiba, v. 8, n. 25, p. 819-839, set./dez. 2008 